\title{
Engineering Saccharomyces pastorianus for the co-utilisation of xylose and cellulose from biomass
}

\author{
William Kricka, Tharappel C James, James Fitzpatrick and Ursula Bond
}

\begin{abstract}
Background: Lignocellulosic biomass is a viable source of renewable energy for bioethanol production. For the efficient conversion of biomass into bioethanol, it is essential that sugars from both the cellulose and hemicellulose fractions of lignocellulose be utilised.

Results: We describe the development of a recombinant yeast system for the fermentation of cellulose and xylose, the most abundant pentose sugar in the hemicellulose fraction of biomass. The brewer's yeast Saccharomyces pastorianus was chosen as a host as significantly higher recombinant enzyme activities are achieved, when compared to the more commonly used S. cerevisiae. When expressed in S. pastorianus, the Trichoderma reesei xylose oxidoreductase pathway was more efficient at alcohol production from xylose than the xylose isomerase pathway. The alcohol yield was influenced by the concentration of xylose in the medium and was significantly improved by the additional expression of a gene encoding for xylulose kinase. The xylose reductase, xylitol dehydrogenase and xylulose kinase genes were co-expressed with genes encoding for the three classes of $T$. reesei cellulases, namely endoglucanase (EG2), cellobiohydrolysase $(\mathrm{CBH} 2)$ and $\beta$-glucosidase $(B G L 1)$. The initial metabolism of xylose by the engineered strains facilitated production of cellulases at fermentation temperatures. The sequential metabolism of xylose and cellulose generated an alcohol yield of $82 \%$ from the available sugars. Several different types of biomass, such as the energy crop Miscanthus sinensis and the industrial waste, brewer's spent grains, were examined as biomass sources for fermentation using the developed yeast strains. Xylose metabolism and cell growth were inhibited in fermentations carried out with acid-treated spent grain liquor, resulting in a 30\% reduction in alcohol yield compared to fermentations carried out with mixed sugar substrates.

Conclusions: Reconstitution of complete enzymatic pathways for cellulose hydrolysis and xylose utilisation in S. pastorianus facilitates the co-fermentation of cellulose and xylose without the need for added exogenous cellulases and provides a basis for the development of a consolidated process for co-utilisation of hemicellulose and cellulose sugars.
\end{abstract}

Keywords: S. pastorianus, Co-utilisation of xylose and cellulose, Biomass, Spent grain fermentations

\section{Background}

Decreasing crude oil reserves and increasing costs of extracting the limited supply of shale gas production through hydraulic fracturing have given increased momentum to finding alternative cost-effective forms of renewable energy sources. Bioethanol and biodiesel can be produced from renewable biomaterials and a variety of food crops including sugarcane, corn and soya bean have been used. However the large-scale use of food crops for fuel may cause long-term food scarcity. An alternative

\footnotetext{
* Correspondence: ubond@tcd.ie

Moyne Institute, School of Genetics and Microbiology, Trinity College Dublin, College Green, Dublin 2, Ireland
}

approach for producing biofuels is the use of carbohydrates extracted from non-food biomass [1,2]. Plant biomass is mainly composed of lignocellulose, which contains three major components cellulose, hemicellulose and lignin. The relative amount of each component varies in different plant types, with an average composition of cellulose $30-50 \%$, hemicellulose $20-30 \%$ and lignin $15-25 \%$ [3].

Cellulose, a $\beta$-glucan linear polymer of $\mathrm{D}$-glucose linked by $\beta$-1,4-glycosidic bonds, is the most abundant polysaccharide on earth [4]. In plants, it is organised into crystalline fibers containing tightly packed microfibrils of approximately $30 \beta$-glucan chains containing some disorganised amorphous regions [5]. Hemicellulose is a 
highly branched heteropolymer composed of pentose and hexose sugars such as xylose, arabinose, mannose, glucose and galactose as well as certain sugar acids [6]. The composition of hemicellulose is variable and depends upon the plant source however glucose and xylose are generally the major hexose and pentose sugars respectively [7]. The third component of lignocellulose, lignin, is a polymer of phenylpropanoid monomers. Lignin links both hemicellulose and cellulose together forming a physical barrier in the plant cell wall [8]. Unlike cellulose and hemicellulose, hydrolysis of lignin does not generate fermentable sugars.

Fermentable sugars, mainly glucose and xylose, can be readily extracted from the hemicellulose fraction of biomass through physical and/or chemical pre-treatments [9]. Glucose is readily metabolised by most organisms via glycolytic pathways. Xylose metabolism occurs mainly in fungal and bacteria species via a pathway requiring two oxidoreductases, xylose reductase (XR) and xylitol dehydrogenase $(\mathrm{XDH})$ or alternatively through the action of a single enzyme, xylose isomerase (XI) [10-13]. The product of both pathways, xylulose, is phosphorylated by xylulose kinase (XKS) and then enters the Pentose Phosphate Pathway (PPP), generating intermediates of the glycolytic pathway [2].

Due to its crystalline nature, the cellulose fraction of biomass is more recalcitrant to sugar extraction, therefore, additional enzymatic hydrolysis, involving the concerted action of three major classes of cellulases, namely endoglucanases (EG), exoglucanases or cellobiohydrolases $(\mathrm{CBH})$ and $\beta$-glucosidases (BGL) is required [2,14]. Endoglucanases cleave the cellulose backbone randomly at amorphous sites along the cellulose fibre exposing new chain ends. Cellobiohydrolases act processively on reducing and non-reducing chain ends to release mainly the disaccharide cellobiose. Finally, $\beta$-glucosidases hydrolyse the $\beta-1,4$ glycosidic bond of cellobiose and cellooligosaccharides to release glucose.

The microorganisim of choice for industrial bioethanol production is the ethanologenic Baker's yeast Saccharomyces cerevisiae, due to its long fermentation history, high ethanol yields and general robustness to environmental stresses encountered during industrial fermentations. However, Saccharomyces species cannot metabolise either xylose or cellulose. While a few natural Saccharomyces isolates have been identified that grow slowly in medium containing xylose as a sole carbohydrate source and several genes encoding putative xylose-utilising enzymes have been identified in the genomes of Saccharomyces species [15,16], xylose metabolism by Saccharomyces species is inefficient and unsuitable for industrial processes and most likely serves as a fail-safe mechanism for survival under conditions when nutrients are limiting. To date genes encoding cellulases have not been identified in yeasts.
To overcome these problems, a recombinant strategy has been pursued in which genes encoding for xylose and cellulose metabolism have been introduced into Saccharomyces species (reviewed in [2,7]). Relatively efficient xylose metabolism has been achieved in yeasts by expressing xenotropic $\mathrm{XR} / \mathrm{XDH}$ or XI genes combined with overexpression of the host encoded XKS gene [17-25]. Further improvements in yields have been obtained through adaptive or directed evolutionary strategies aimed at increasing metabolic fluxes through the PPP or altering co-factor requirements for the xylose utilising enzymes [17,26-30]. Likewise, recombinant cellulases, in secreted- or cell tethered-forms, have been produced in yeasts to allow for extracellular hydrolysis of cellulose [2,31-39]. Fermentations using cellulose as a sole carbohydrate source are hampered by a 'chicken and egg' conundrum, as cellulase production and secretion by the recombinant yeast requires cell growth but this is limited at early stages of fermentation by the lack of fermentable sugars [2]. This problem is currently overcome by the addition of exogenous cellulases to the fermentation medium, however this adds substantial costs to the process.

While $S$. cerevisiae remains the host of choice for heterologous expression of cellulases and xylose utilising enzymes, we recently demonstrated that up to ten times higher levels of cellulase activity is attained from recombinant proteins expressed in the brewer's yeast Saccharomyces pastorianus, when compared to the levels produced in $S$. cerevisiae strains [35].

To date, alcohol production from either cellulose or xylose has been examined separately using $S$. cerevisiae engineered to produce either cellulases or xylose utilising enzymes respectively, however for efficient and economic conversion of biomass to bioethanol, the utilisation of both the hemicellulose and cellulose fractions of lignocellulose will be required. As a first step to generating yeast strains with a capacity to ferment hemicellulosic and cellulosic sugars, genes encoding $\beta$-glucosidase (bgll) together with the xylose utilising genes $x r / x d h / X K S$ have been introduced into $S$. cerevisiae [40,41]. Alcohol production from xylose and cellobiose using the engineered strains was observed however for fermentation of cellulose, the engineered system still required the addition of exogenous cellulases [42].

To generate a yeast strain for fermenting both xylose and cellulose from biomass, without the need for added exogenous cellulases, we reconstituted the complete enzymatic pathways for cellulose degradation and xylose utilisation in a stress-tolerant strain of S. pastorianus by co-expressing all three classes of cellulases genes ( $b g l 1$, eg2, cbh2) with the $x y l 1 / x d h 1 / X K S$ genes. In fermentations using xylose and cellulose as sole carbohydrate sources, the engineered strains initially utilises xylose, facilitating cell growth and the synthesis and secretion of cellulases, allowing for continued fermentation and 
alcohol production from cellulose, without the need for added exogenous cellulases.

\section{Results}

\section{Choice of host}

We previously observed that expression of recombinant cellulase genes in the brewer's yeasts, S. pastorianus, produced significantly higher enzyme activities when compared to the activity observed in S. cerevisiae [35]. S. pastorianus are generally tetraploid hybrid yeasts containing both $S$. cerevisiae and S. eubayanus genomes [43-45]. To determine if a similar enhancement of enzyme activity could be achieved for the xylose utilising enzymes, we compared the activity of $T$. reesei xyl 1 and $x d h 1$ genes in haploid and tetraploid isogenic S. cerevisiae strains, and in the tetraploid S. pastorianus, CMBS51. The latter is a stress-tolerant derivative of a typical lager yeast CMBS-33. The activities of both enzymes were significantly higher in S. pastorianus when compared to the activities in the haploid or tetraploid S. cerevisiae strains (Figure 1A). Since it was possible that increased enzyme activity in S. pastorianus resulted from the presence of the S. eubayanus genome, we also examined the activities in the parental strain S. eubayanus, however in this species, the enzyme activities were also substantially lower than that observed in S. pastorianus (Figure 1A). Using an $X D H$-GFP fusion protein (Table 1), we observed that increased enzyme activity directly correlated with increased recombinant protein levels (Figure 1B).

\section{Comparison of the XR/XDH and XI pathways in $S$. pastorianus}

The $\mathrm{XR} / \mathrm{XDH}$ oxidoreductase pathway requires the cofactors NADPH and $\mathrm{NAD}^{+}$in the forward reactions respectively. This can lead to redox imbalances within the cell resulting in inefficient xylose utilisation. The alternative XI pathway allows xylose metabolism in a single step and has no co-factor requirement [7]. We compared xylose metabolism by the two pathways in $S$. pastorianus expressing the respective genes. Cells coexpressing the $x y l 1 / x d h 1$ genes were capable of growing on xylose while expression of either gene individually did not support growth (Figure 2A). Cells expressing $x i$ were unable to grow on SC-xylose (Figure 2A), however, xylose utilisation, albeit in low levels, was detected when the strain was cultured in rich YEP media with xylose as the sole carbohydrate source (Figure 2B). Xylose utilisation was substantially higher in cells expressing the $x y l 1 /$ $x d h 1$ genes (Figure 2B), which produced up to 7 times more alcohol, with levels reaching $8.8 \mathrm{~g} \mathrm{~L}^{-1}$ (Figure 2C).

While the $\mathrm{XR} / \mathrm{XDH}$ pathway produced more alcohol than the XI pathway, the alcohol yield from xylose was

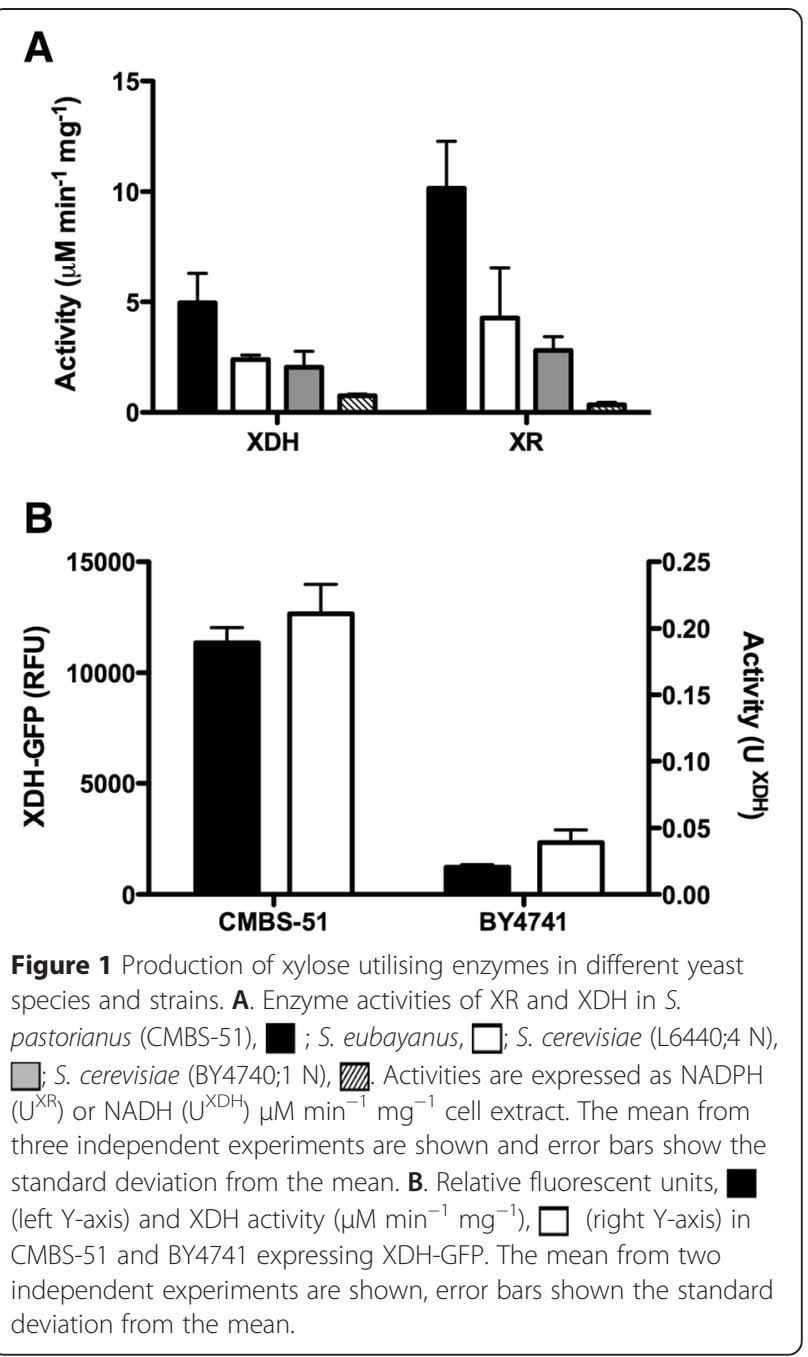

still relatively low (39\%). To improve this yield, the native $S$. cerevisiae xylulose kinase gene, $X K S 1$, was overexpressed in S. pastorianus in conjunction with the xyl1$x d h 1$ genes. The additional expression of XKS1 increased alcohol levels approximately 3 -fold, representing a $64 \%$ conversion of xylose to alcohol (Figure 3A). The increased production of alcohol in the presence of XKS1 was dependent on the starting concentration of xylose. Lowering the starting concentration of xylose from 5\% to $2 \%$ abrogated the influence of $X K S 1$ overexpression on the final alcohol yield, however the rate of alcohol production at the lower xylose concentration was still faster with XKS1 over-expression (Figure 3B). Growth on xylose (Figure 2A) and the rate of xylose uptake from the medium was similar in cells expressing $x y l 1 / x d h 1$ and $x y l 1 / x d h 1 / X K S 1$ at both low (2\%) and high concentrations (5\%), however at the lower concentrations, xylose was more rapidly depleted from the medium (Figure $3 \mathrm{C}$ and $\mathrm{D}$ ). 
Table 1 Gene cassettes

\begin{tabular}{|c|c|c|c|c|}
\hline Plasmid & Primers & & Starting plasmid & Insertion site \\
\hline TEFbg/1* & bgl1_Rec1F & bgl1_Rec2R & $\mathrm{pRS} 42 \mathrm{H}$ & Sal1 \\
\hline PGKbg/1* & bgl1_Rec1F & bgl1_Rec2R & $\mathrm{pRS} 42 \mathrm{H}$ & Sal1 \\
\hline TEFcbh2* & cbh2_Rec1F & cbh2_Rec2R & $\mathrm{pRS} 42 \mathrm{H}$ & Sal1 \\
\hline \multirow[t]{2}{*}{ PGKegl2* } & egl2_Rec1F & egl2_MidR & $\mathrm{pRS} 42 \mathrm{H}$ & Sal1 \\
\hline & egl2_MidF & egl2_Rec2R & & \\
\hline PGKxy/1 & xyl1F & xyl1R & pRS42H_PGKbg/1 & Sal1 \\
\hline PGKxdh1 & $x d h F$ & $x d h R$ & pRS42H_PGKbg/1 & Sal1 \\
\hline PGKxi & xiF, xiMidF & xiMidR, xiR & pRS42H_PGKbgl1 & Sal1 \\
\hline PGKxdh1GFP & $x d h F, G F P F$ & xdh1GFPR, GFPR & pRS42H_PGKbgl1 & Sal1 \\
\hline TEFXKS1 & Psi_TEFF, xks_MidF & xks_MidR, Psi_CycR & pRSK42K & Psi1 \\
\hline PGKxyl1-PGKxdh1 & Psi_PGKF xr_MidF & xr_MidR Psi_CycR & pRS42H_PGKxdh1 & Psi1 \\
\hline PGKxyl1-TEFXKS1-PGKxdh1 & Acc_TEFF, xks_MidF & xks_MidR, AccR & pRS42H_PGKxyl1-PGKxdh1 & Acc65l \\
\hline PGKxy/1-TEFbg/1-PGKxdh1 & Acc_TEFF, bgl1_MidF & bgl1_MidR, AccR & pRS42H PGKxy/1-PGKxdh1 & Acc65l \\
\hline PGKxyl1-TEFcbh2-PGKxdh1 & Acc_TEFF, cbh2_MidF & cbh2_MidR, AccR & pRS42H PGKxy/1-PGKxdh1 & Acc65l \\
\hline PGKxyl1-PGKeg/2-PGKxdh1 & Acc_PGKF, egl2_MidF & egl2_MidR, AccR & pRS42H PGKxy/1-PGKxdh1 & Acc65l \\
\hline
\end{tabular}

*Reference [35], all other strains generated in this study.

\section{Ethanol production from xylose and cellulose fermentations}

To optimise for alcohol production from biomass, it is essential that sugars be extracted from both the hemicellulose and cellulose fractions. We previously cloned and expressed copies of the $T$. reesei genes egl2, bgll and $c b h 2$, encoding for the three classes of cellulase enzymes, into S. pastorianus and demonstrated that the recombinant enzymes act synergistically to degrade the cellulose substrate, PASC [35]. To develop a consolidated process for the utilisation of both hemicellulose and cellulose sugars, each of the cellulase genes were co-expressed
A

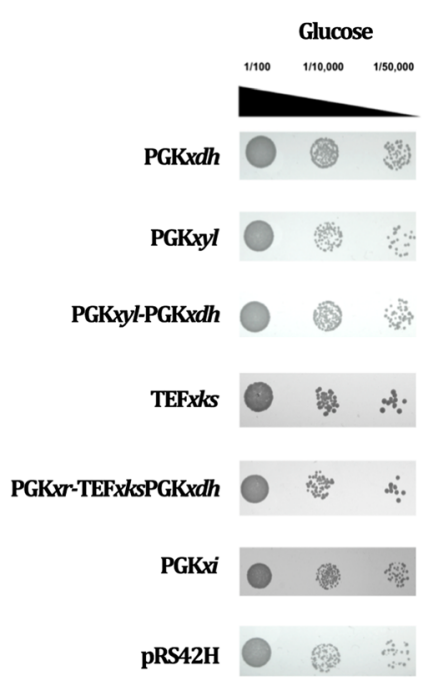

B

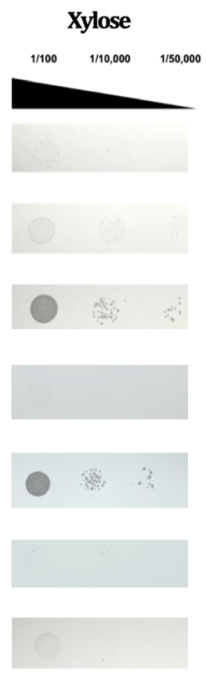

C
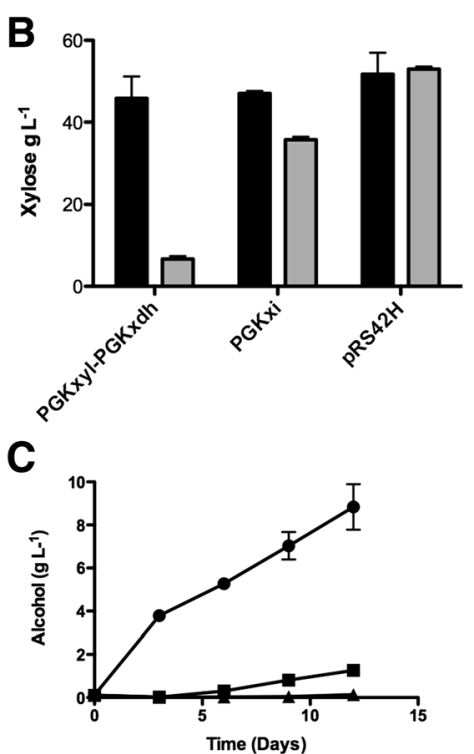

Figure 2 Xylose metabolism in S. pastorianus. A. S. pastorianus, carrying gene cassettes (shown on the left; Table 1) coding for T.reesei xylose metabolising enzymes, were grown initially in YEPD. The cells were harvested, washed and resuspened in SC-glucose or SC-xylose media. Various dilutions of the cells were plated onto SC-glucose and SC-xylose agar plates. B. Xylose utilization in S. pastorianus expressing $x d h 1 / x y \mid 1$, xi, or the empty vector pRS42H. Xylose concentration $\left(\mathrm{g} \mathrm{L}^{-1}\right)$ in the medium on Day 0, $\square$ and Day 12, $\square$ are shown. C. Alcohol $\left(\mathrm{g} \mathrm{L}^{-1}\right)$ produced by S. pastorianus

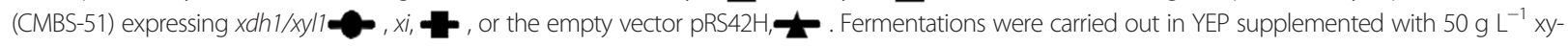
lose. The values represent the mean of duplicate independent experiments and error bars show the standard deviation from the mean. 

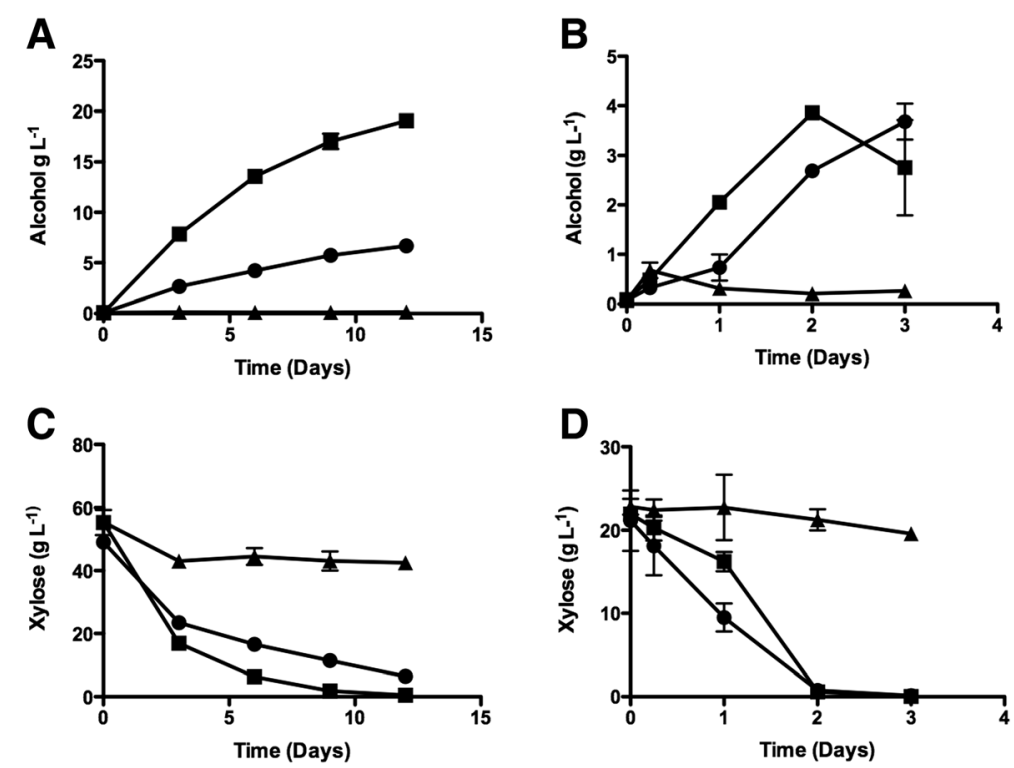

Figure 3 Co-expression of XKS improves alcohol yield in S. pastorianus. Alcohol(g $\left.\mathrm{L}^{-1}\right)$ production (A, B) and xylose utilization (C, D) by S.

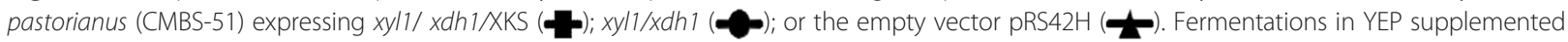
with $50 \mathrm{~g} \mathrm{~L}^{-1}$ (A and C) or $20 \mathrm{~g} \mathrm{~L}^{-1}$ (B and D) xylose were carried for 12 days and samples taken at the intervals shown. The values represent the mean of triplicate independent experiments and error bars show the standard error from the mean.

with the $x y l 1 / x d h$ genes on a single plasmid (Table 1 ). The XKS1 gene was supplied in trans on a separate plasmid (Table 1). The activities of XR and XDH were not affected by the additional expression of the cellulase genes on the same plasmid and likewise cellulase activities were unaffected by co-expression of the $x y l 1$ and $x d h 1$ (data not shown).

Fermentations were carried out using co-cultures of $S$. pastorianus containing the triple expressing plasmids (PGKxyl1-TEFbgl1-PGKxdh1, PGKxyl1-TEFcbh2-PGK $x d h 1$ and PGKxyl1-PGKegl2-PGKxdh1; Table 1) in medium containing xylose only, PASC only or both as carbohydrate sources. Yeast cultures grown on PASC as a sole carbohydrate source produced little if any alcohol due to the lack of enzyme activity and cell growth at a fermentation temperature of $30^{\circ} \mathrm{C}$ [35] (Figure 4A). Cultures grown on xylose produced up to $5.4 \mathrm{~g} \mathrm{~L}^{-1}$ alcohol, however, fermentations containing both xylose and PASC produced almost twice as much alcohol $\left(9.6 \mathrm{~g} \mathrm{~L}^{-1}\right)$, indicating that xylose metabolism supports cellulase production by yeasts, thus enabling a co-fermentation of both xylose and cellulose at mesothermal fermentation temperatures. The additional co-expression of the XKS1 gene on a separate plasmid (TEFXKS1, Table 1) together with the triple expressing plasmids (PGKxyl1-TEFbgl1-PGKxdh1, PGKxyl1-TEFcbh2PGKxdh1 and PGKxyl1-PGKegl2-PGKxdh1) substantially increased alcohol production, increasing the yield 2.6-fold (Figure 4B). In cells overexpressing XKS1, xylose is metabolised in preference to cellulose at the early stages of the fermentation. Cellulose metabolism is not observed until day 10 and thereafter alcohol production for the mixed sugars (xylose and PASC) is statistically different from that produced from xylose alone (Figure 4B). The alcohol yield from PASC, xylose, and mixed sugars (xylose and PASC) was $0.14 \%, 73.5 \%$, and $82.2 \%$ respectively at the end of the fermentation. Since the maximum yield of ethanol from PASC at the concentration used is $5 \mathrm{~g} \mathrm{~L}^{-1}$, the increased yield of ethanol in the mixed sugars fermentation is accounted for by complete hydrolysis of the PASC present.

\section{Sugar extraction from energy crops and industrial waste}

Several different types of biomass were examined as sugar sources for fermentation using the developed yeast strains. The energy crops, $M$. sinensis, $M$ giganteus and E. nitens, as well as industrial waste in the form of spent grains from both industrial and microbreweries were pre-treated as described in the Methods section and the glucose and xylose content of the extracted liquor was determined (Table 2). Increasing the starting concentration of biomass resulted in an increase of the concentration of extracted sugars (data not shown). The xylose content of the liquor was relatively similar in all biomass sources with the exception of M. giganteus which showed lower levels in both stem and leaf portions. The glucose content of the different biomass sources was more varied. The highest glucose content was found in spent grains, however there was a high variability between batches of spent grains sourced from different 

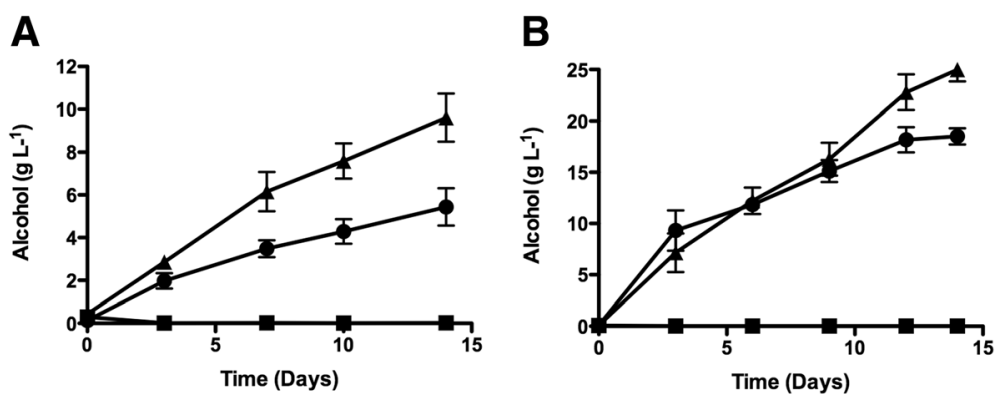

Figure 4 Co-fermentation of xylose and cellulose (PASC). S. pastorianus (CMBS-51) expressing the gene cassettes (A) PGKxy/1-TEFbg/1-PGKxdh1, PGKxyl1-TEFcbh2-PGKxdh1 and PGKxyl1-PGKegl2-PGKxdh1 or (B) additionally PGKXKS in trans were individually cultured in YEPD. Cells were harvested, combined in a 1:1:1 ratio and used to inoculate fermentations containing PASC ( $\mathbf{-})$ ), xylose ( $\mathbf{-}$ ), or PASC and xylose ( $\boldsymbol{\mathcal { C }}$ ). The concentrations of PASC and xylose were $412 \mathrm{~g} \mathrm{~L}^{-1}$ and $40 \mathrm{~g} \mathrm{~L}^{-1}$ for (A) and $412 \mathrm{~g} \mathrm{~L}^{-1}$ and $50 \mathrm{~g} \mathrm{~L}^{-1}$ for (B) respectively. Fermentations were conducted at $30^{\circ} \mathrm{C}$ for 14 days and samples were taken at the intervals shown and alcohol content ( $\mathrm{g} \mathrm{L}^{-1}$ ) assayed. The values represent the mean of triplicate $\mathbf{( A )}$ or quadruplicate $\mathbf{( B )}$ independent experiments and the error bars represent the standard error from the mean.

breweries with glucose concentrations ranging from 5.3 - $31 \mathrm{~g} \mathrm{~L}^{-1}$ (Table 2). The E. nitens biomass showed the lowest glucose content.

\section{Alcohol production from spent grains}

Due to its relatively high xylose and glucose content, spent grain liquor (SGL) was chosen for further analysis as a medium for fermentation. For consistency, fermentations were conducted using the liquor from a single batch of spent grain. Glucose and xylose consumption, and alcohol production were compared between fermentations carried out with SGL or with a mixture of purified xylose and glucose at the same concentrations as found in the SGL (Figure 5). Glucose was rapidly consumed within 24 hours from both the purified sugar mixture and the SGL, although a slight lag was observed in the latter fermentation (Figure 5A). Xylose consumption in both fermentations was much slower than glucose consumption: in the purified sugar mixture, xylose was not depleted until 120 hrs (Figure 5B). Strikingly, xylose consumption was severely inhibited in the SGL fermentation (Figure 5B). While up to $15 \mathrm{~g} \mathrm{~L}^{-1}$ alcohol was produced from the xylose/glucose fermentation (Figure $5 \mathrm{C}$ ), the SGL fermentations produced $10 \mathrm{~g} \mathrm{~L}^{-1}$ alcohol after 24 hours with levels decreasing slightly thereafter, suggesting some degree of alcohol catabolism

Table 2 Glucose and xylose extraction from biomass

\begin{tabular}{|c|c|c|}
\hline Biomass (100 g L) & Xylose $\mathrm{g} \mathrm{L}^{-1}(\mathrm{sd})$ & Glucose $\mathrm{g} \mathrm{L}^{-1}(\mathrm{sd})$ \\
\hline Spent Malt Grain & $11.64(2.13)$ & $16.97(13.11)$ \\
\hline M.sinensis Leaf & $11.82(0.65)$ & $3.70(0.47)$ \\
\hline M.sinensis Stem & $12.18(1.10)$ & $9.56(2.55)$ \\
\hline M.giganteus Leaf & $8.33(1.06)$ & $6.25(2.24)$ \\
\hline M.giganteus Stem & $4.98(1.86)$ & $11.19(0.28)$ \\
\hline E. nitens & $15.71(0.64)$ & $0.98(0.09)$ \\
\hline
\end{tabular}

sd; standard deviation. at late stages of the fermentation (Figure 5C). The alcohol consumption appears to result from a lack of xylose metabolism as fermentations carried out with yeast cells containing the empty vector showed a similar marked alcohol consumption at the later stages of fermentation (Figure 5C), indicating that xylose metabolism allows continued alcohol production in mixed sugar and SGL fermentations.

The lower level of alcohol production in the SGL fermentation appears to be due to cell growth inhibition. This growth retardation is evident when SGL fermentations were inoculated with yeast cultures at low cell densities (Figure 5D). At the high cell densities used in the actual fermentations, very little cell growth is observed, nevertheless, even at these high cell densities, the growth in SGL and mixed sugar fermentations was significantly different (data not shown). The inhibition of cell growth did not affect enzyme production as enzyme activity per cell was not significantly different in mixed sugar and SGL fermentations (data not shown).

\section{Discussion}

For the efficient use of biomass for bioethanol production, it is essential that sugars from both the hemicellulose and cellulose fractions of lignocellulose be utilised. Here, we developed yeasts strains capable of co-utilising cellulose and xylose, the most abundant pentose sugar in the hemicellulose fraction of biomass as carbohydrate substrates.

While S. cerevisiae remains the host of choice for heterologous expression of recombinant proteins, we confirm our previous finding that the enzyme activity of recombinant proteins is substantially higher in the lager yeast S. pastorianus. Enzyme activity of $x y l 1$ and $x d h 1$ were significantly higher in S. pastorianus compared to the activities achieved in a haploid $S$. cerevisiae strain or an isogeneic tetraploid strain or in $S$. eubayanus, 


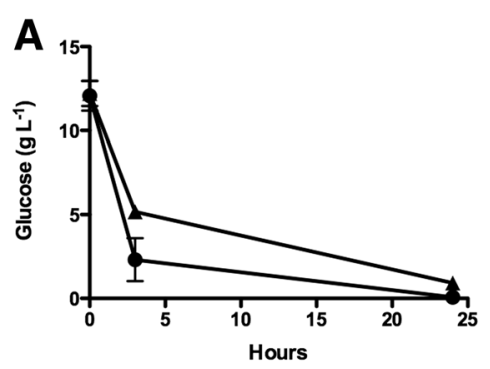

B
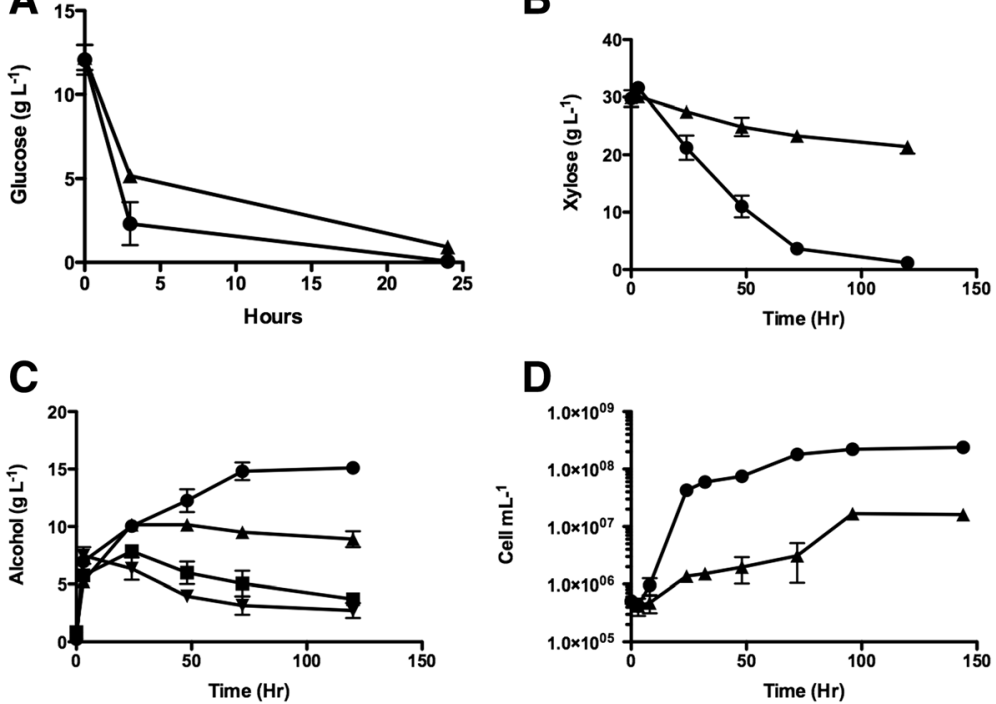

Figure 5 Fermentation of pre-treated biomass liquor. Fermentations were carried out with S. pastorianus strains expressing the gene cassettes PGKxyl1-TEFXKS-PGKxdh1 in YEP media supplemented with spent grain liquor (-) or with purified sugars (xylose $30 \mathrm{~g} \mathrm{~L}^{-1}$ and glucose $11 \mathrm{~g} \mathrm{~L}^{-1}$ ) (-). Fermentations were conducted at $30^{\circ} \mathrm{C}$ for 5 days and samples were taken at the intervals shown and assayed for $\mathbf{A}$. Glucose ( $\mathrm{g} \mathrm{L}^{-1}$ ), $\mathbf{B}$. Xylose $\left(\mathrm{g} \mathrm{L}^{-1}\right.$ ) and $\mathbf{C}$. Alcohol ( $\left.\mathrm{g} \mathrm{L}^{-1}\right)$. Control fermentations with S. pastorianus containing the empty vector pRSH42 in spent grain liquor ( $\mathbf{F}$ ) or with purified sugars (-) are also shown in C. Panel D; cell growth profile of S. pastorianus in SGL, $\mathbf{C}$ and mixed sugar (xylose and glucose), - at various times. Cells were inoculated at low cell density $\left(1 \times 10^{5}\right.$ cell/mL). Mean values from triplicate experiments are shown and error bars indicate the standard error from the mean.

suggesting that both the ploidy of the strains and the genome content are contributing to the observed increased enzyme activities. Increased enzyme activity appears to result from increased recombinant protein levels in $S$. pastorianus as assessed by XDH-GFP fusion proteins. The basis for the increased recombinant protein levels in $S$. pastorianus remains unclear at present but may result from slower protein turnover as a consequence of the slow growth rate of $S$. pastorianus at $30^{\circ} \mathrm{C}$ [35].

Several problems have been encountered in developing yeast strains capable of ultilising xylose. The redox imbalance resulting from the XR/XDH pathway remains a significant barrier to complete xylose utilisation particularly under strict anaerobic conditions. For this reason, several groups have examined the use of the XI pathway for xylose utilisation. Here we compared xylose utilisation via the two pathways in S. pastorianus. Higher alcohol levels are generated from xylose by the XR/XDH pathway compared to the XI pathway confirming previous findings using $S$. cerevisiae as a host $[46,47]$.

We uncovered several factors that influence xylose utilisation in $S$. pastorianus. Overexpression of the $S$. cerevisiae XKS1 gene in S. pastorianus coupled with increasing the xylose concentration in the medium substantially improved alcohol production. High starting concentrations of xylose appear to allow cells to remain in a fermentative state for longer thus promoting alcohol production. Taken together, the data suggests that efficient xylose utilisation requires both high substrate concentrations and efficient forward reactions to drive metabolic fluxes towards alcohol production.

We used the previously developed $S$. pastorianus strains to examine the co-utilisation of xylose and cellulose. Hydrolysis of cellulose and its use a sole carbohydrate source in mesothermal fermentations is severely impeded by a classic "chicken and egg" conundrum: for cellulase production, cell growth is required but on the other hand, cell growth is retarded by the lack of available fermentable sugars prior to cellulose hydrolysis. Additionally, optimum activity of cellulases is achieved at temperatures in the range of $50-60^{\circ} \mathrm{C}$ and is significantly reduced at $30^{\circ} \mathrm{C}$, the optimum temperature for mesophilic yeast fermentations [35]. We observed that co-expression of xylose metabolising enzymes alleviates this problem by facilitating the production of cellulases at fermentation temperatures and the subsequent hydrolysis of the cellulose during the fermentation. Thus a consolidated fermentation process, utilising both xylose and cellulose, is superior to either process individually.

While being a useful model for examining the activities of recombinant enzymes, the use of carbohydrate substrates like purified xylose and PASC does not reflect the complexity of natural biomass sources. Firstly, chemical or physical pre-treatments are necessary to release fermentable sugars from biomass, however, inhibitory 
molecules such as acetic acid, furfurals and phenols produced during this process can severely affect alcohol yields and cell growth [48]. Of the biomass sources examined in this study, spent grains appeared to be the most suitable for alcohol production, displaying high yields of both xylose and glucose. Alcohol production was inhibited by approximately 30\% in fermentations carried out in SGL when compared to fermentations carried out with a purified sugar mixture containing similar ratios of xylose and glucose. While the glucose present in SGL is readily fermentable, we show that xylose utilisation is severely inhibited. The decrease in xylose utilisation was not due to a direct effect on the enzyme activities but instead appears to result from an inhibition of cell growth. Metabolome analysis of xylose utilisation in the presence of inhibitors revealed the accumulation of various non-oxidative PPP intermediates [49], indicating a bottleneck in PPP metabolism. This inhibition can be partially relieved by overexpression of a PPP transaldolase, TAL1 $[49,50]$. The transcriptome analysis of cells grown in the presence of inhibitors also revealed reduced levels of certain transcripts coding for proteins not only required for carbohydrate metabolism but also, for transcriptional and translational control indicating a pleotrophic effect of inhibitors on cell metabolism $[48,51]$.

To improve the fermentation efficiency of biomass, it is clear that the presence of inhibitors must be addressed. Chemical removal of inhibitors has been attempted [52-54], although this approach increases processing costs. Alternatively, adaptive evolutionary or directed mutagenesis approaches have been used to improve tolerance of yeast to these inhibitors [30,55-58]. The high degree of genome plasticity in S. pastorianus facilitates such adaptive evolutionary approaches $[59,60]$. Other strategies involve metabolism of the inhibitors, thus reducing the concentrations in the medium [61].

The hydrolysis of cellulose remains the rate-limiting step in bioethanol production from biomass. This coupled with the observed slower cell growth rate of yeast cultures in biomass liquor and reduced xylose utilisation impedes the development of a consolidated biomass fermentation process. Success for this goal is heavily dependent to the development of yeast strains with improved cell growth and xylose utilisation in biomass fermentations and improved cellulase production in these strains.

\section{Methods and materials}

\section{Strains and media}

Strain CMBS-51 is a stress tolerant derivative of the $S$. pastorianus yeast strain CMBS-33 (James et al. [59]). The tetraploid laboratory S. cerevisiae yeast strain (L6440) was a gift from the Fink laboratory (Massachusetts Institute of
Technology, Boston, MA). The haploid S. cerevisiae strain BY4741 was purchased from EuroScARF. Saccharomyces eubayanus was obtained from the Portuguese Yeast Culture Collection (PYCC; Faculdade de Ciências e Tecnologia, Universidade Nova de Lisboa (FCT/UNL, Caparica). Yeast cultures were grown at $30^{\circ} \mathrm{C}$ for $24 \mathrm{~h}$ in Yeast Extract Peptone (YEP; $10 \mathrm{~g}^{\text {litre }}{ }^{-1}$ yeast extract, $20 \mathrm{~g} \mathrm{litre}^{-1}$ peptone) supplemented with $20-50 \mathrm{~g}$ litre $^{-1}$ glucose (D), sucrose $(\mathrm{S})$ or xylose $(\mathrm{X})$ ). For plate growth assays, cultures were grown overnight in YEPD then spotted onto synthetic complete (SC) agar (20 g litre ${ }^{-1}$ agar, $1.7 \mathrm{~g} \mathrm{litre}^{-1}$ yeast nitrogen base, $0.5 \mathrm{~g}$ litre $^{-1}$ ammonium sulphate, $0.59 \mathrm{~g}$ litre $^{-1}$ yeast synthetic drop-out medium, $0.2 \mathrm{~g}$ litre $^{-1}$ adenine, $0.03 \mathrm{~g}$ litre $^{-1}$ uracil, $0.12 \mathrm{~g}$ litre ${ }^{-1}$ lysine, $0.08 \mathrm{~g}$ litre $^{-1}$ tryptophan, $0.08 \mathrm{~g}$ litre $^{-1}$ leucine and $0.02 \mathrm{~g}$ litre $^{-1}$ histidine) containing X or D $\left(20 \mathrm{~g} \mathrm{litre}^{-1}\right)$ and incubated for 5 days at $30^{\circ} \mathrm{C}$. For cultivation of yeast cultures bearing plasmids, the media was supplemented with hygromycin $\left(300 \mu \mathrm{g} \mathrm{mL}^{-1}\right)$ or the aminoglycoside Geneticin (G418; $200 \mu \mathrm{g} \mathrm{mL} L^{-1}$ ) where appropriate. Xylose and glucose concentrations in culture media were determined using Xylose Mutarotase (Megazyme International, Bray, Ireland) or Glucose (GAHK20; Sigma-Aldrich) assay kits respectively as per manufacturers instructions. Phosphoric acid swollen cellulose (PASC) was prepared as described previously [35].

\section{Gene cloning and expression strategy Sources of DNA}

The $T$. reesei cellulase genes, $b g l 1, e g l 2$ and $c b h 2$ were previously cloned and expressed under the control of the $S$. cerevisiae Phosphoglycerate kinase (PGK) or translation elongation factor $1 \alpha$ (TEF) promoters and downstream CYC terminator sequence into the high copy number plasmid pRHS42H [35] (Table 1). Gene information for $x y l 1$ and $x d h 1$, encoding for $\mathrm{XR}$ and $\mathrm{XDH}$ respectively, were sourced from The Joint Genome Institute (http://genome.jgi-psf.org/Trire2/Trire2.home.html). The genes were PCR amplified from $T$. reesei genomic DNA (QM9123) in overlapping DNA fragments using primers designed to remove intronic sequences. The XKS1 gene sequence was amplified from S. cerevisiae (S288c) genomic DNA. The protein sequence for Piromyces sp Xylose Isomerase (xi) (www.ebi.ac.uk; ID TR:Q9P8C9_PIRSE) was reverse translated (yeast codon optimised) using GeneDesign [62]. The DNA sequence was synthesised and cloned into pUC57 by GenScript. Inc. (Piscataway, NJ).

\section{Modular cloning strategy}

A modular gene cloning strategy as previously outlined in [63] and modified in [35] was implemented to generate single, double or triple gene expression cassettes on the high copy number plasmids pRS42H or pRSH42K, 
which contain genes encoding for Hygromycin or G418 aminoglycoside resistance respectively [64]. The starting plasmid was either pRS42H PGK-bgl1-CYCT or TEFbgl1-CYCT in which the $T$. reesei bgll gene is under the control of the S. cerevisiae PGK or TEF promoters respectively and upstream of the S. cerevisiae CYC terminator [35]. The bgl1 gene and/or promoter were excised out by Sal1 cleavage (Table 1) and the PCR generated replacement gene cassettes inserted into the plasmid by in vivo homologous recombination, following transformation into S. pastorianus as described previously [35].

For multiple gene expression, gene cassette 2 (promoter, gene and terminator) was inserted at the Psil site on the plasmid at position -562 relative to the PGK promoter of gene cassette 1 and in the same orientation by homologous recombination in vivo. For triple gene expression, gene cassette 3 (promoter, gene and terminator) was inserted at the Acc65I site at position -5 relative to gene cassette 1 and in the same orientation (Table 1). The gene cassettes were amplified in one or two fragments, in the latter case with oligonucleotide primers containing overlapping sequence homology. The names of the primers used for each gene amplification are listed in Table 1 and the sequences of the oligonucleotide primers are listed in Additional file 1: Table S1.

\section{$\mathrm{XDH}$ and XR activity}

Yeast strains expressing the $x y l 1$ and $x d h 1$ genes were cultured in YEPD for $24 \mathrm{~h}$ at $30^{\circ} \mathrm{C}$. The cells were harvested, washed twice in lysis buffer $(250 \mathrm{mM}$ potassium phosphate pH7.0) and re-suspended in 1/10 of the original volume of the same buffer. The cells were lysed using Zirconia beads (Biospec Inc., Bartlesville, OK) with agitation at $4^{\circ} \mathrm{C}$ (Vibrax; IKA-Werke $\mathrm{GmbH}$, Staufen, Germany) and the cell debris was removed by centrifugation. Protein concentrations of cell-free extracts were quantified using Bradford reagent and bovine serum albumin (BSA) as a standard $(0-2 \mathrm{mg} / \mathrm{mL})$.

$\mathrm{XDH}$ activity was quantified by measuring the reduction of nicotinamide adenine dinucleotide $\left(\mathrm{NAD}^{+}\right)$to NADH. Briefly, the cell-free extract was mixed in a 1:10 ratio with a reaction buffer consisting of $0.15 \mathrm{M}$ xylitol, $0.4 \mathrm{mM} \mathrm{NAD}^{+}$and $25 \mathrm{mM}$ potassium phosphate $\mathrm{pH}$ 7.0. NADH production was monitored by the change in absorbance at $340 \mathrm{~nm}$. XDH activity was defined as NADH $(\mu \mathrm{M})$ produced per minute using a standard curve $(0-800 \mu \mathrm{M}$ NADH). The crude specific activity was defined as the rate of reaction divided by the protein concentration of the cell lysate $\left(\mathrm{U}^{\mathrm{XDH}}, \mu \mathrm{M} \mathrm{min}^{-1} \mathrm{mg}^{-1}\right)$.

The XR activity was quantified by measuring the oxidation of the reduced form of nicotinamide adenine dinucleotide phosphate (NADPH). Cell-free extract was mixed in a 1:10 ratio with a reaction buffer containing $0.34 \mathrm{mM}$ NADPH, $50 \mathrm{mM}$ xylose and $25 \mathrm{mM}$ potassium phosphate $\mathrm{pH} 7.0$ and incubated at $30^{\circ} \mathrm{C}$. $\mathrm{NADP}^{+}$production was monitored by the change in absorbance at $340 \mathrm{~nm}$. XR activity was defined as NADPH $(\mu \mathrm{M})$ oxidised per minute using a standard curve $(0-680 \mu \mathrm{M}$ $\mathrm{NADPH})$. The crude specific activity was defined as the rate of reaction divided by the protein concentration of the cell lysate $\left(\mathrm{U}^{\mathrm{XR}}, \mu \mathrm{M} \mathrm{min}^{-1} \mathrm{mg}^{-1}\right)$.

\section{GFP quantification}

Strains expressing the $x d h$-GFP gene (Table 1$)$ were cultured in YEPD at $30^{\circ} \mathrm{C}$ for $24 \mathrm{Hrs}$. Approximately $7 \times 10^{8}$ cells were harvested by centrifugation and washed thor-

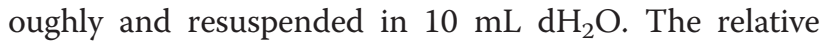
fluorescence $(\mathrm{RF})$ of the cell sample $(100 \mu \mathrm{L})$ was measured in a Take 3 micro-volume plate using a Synergy H1 Hybrid reader (Biotek Inc., Winooski, VT). The excitation and emission wavelengths were set at $480 \mathrm{~nm}$ and $510 \mathrm{~nm}$ respectively.

\section{Biomass pre-treatment}

Miscanthus sinensis and Miscanthus giganteus were obtained from Dr. Trevor Hodgekinson (Botany Department, Trinity College Dublin). Eucalyptus nitens was supplied by Dr. Denis Lobby, DL Biotechnology, Co. Carlow. Spent grains were obtained from St James Gate Brewery, Diageo, Dublin or from the Five Lamps Microbrewery, Dublin. All biomass was dried at $60^{\circ} \mathrm{C}$ for $48 \mathrm{hrs}$. The stems and leaves of the plant material were separated, and then milled using a kitchen blender (Phillips) for 5 minutes at full speed. Sulphuric acid (4\% $\mathrm{w} / \mathrm{v}$ ) was added to the dried biomass at a concentration of $5-12.5 \mathrm{~g}$ per $50 \mathrm{~mL}$. The slurry was heated in a pressure cooker (Moulinex, Minut' cook) on the low pressure setting for 40 minutes and then centrifuged to separate the soluble and insoluble material. The soluble fraction (liquor) was neutralised by addition of $\mathrm{NaOH}$ until a pH 5.5 was reached and then was passed through a Whatman No.1 filter, to remove any insoluble biomass.

\section{Fermentation conditions}

Fermentations were carried out in sealed conical flasks at $30^{\circ} \mathrm{C}$ under microaerophilic conditions in medium composed of YEP $\left(30 \mathrm{~g} \mathrm{~L}^{-1}\right)$ supplemented with $412 \mathrm{~g}$ $\mathrm{L}^{-1}$ PASC, $42-50 \mathrm{~g} \mathrm{~L}^{-1}$ xylose, or with both $412 \mathrm{~g} \mathrm{~L}^{-1}$ PASC and $42-50 \mathrm{~g} \mathrm{~L}^{-1}$ xylose. The concentration of available glucose in $412 \mathrm{~g} \mathrm{~L}^{-1}$ PASC is $10.3 \mathrm{~g} \mathrm{~L}^{-1}$ [35]. For spent grain liquor fermentations, the neutralised liquor was supplemented with YEP $\left(30 \mathrm{~g} \mathrm{~L}^{-1}\right)$ and then filter sterilised by passage through a $0.2 \mu \mathrm{m}$ Polyethersulfone (PES) syringe filter. The media were inoculated at a high cell density $\left(1 \times 10^{8}\right.$ cell $\left.\mathrm{mL}^{-1}\right)$, with yeast cells pre-grown in YEPD for $24 \mathrm{~h}$. Where applicable, $300 \mu \mathrm{g} /$ $\mathrm{mL}$ hygromycin (Foremedium, Hunstanton, UK) or 
$200 \mu \mathrm{g} / \mathrm{mL}$ Geneticin (G418;Invivogen, San Diageo, CA, U.S.A.) was added to the cultures.

\section{Quantification of alcohol}

Alcohol production was determined using the alcohol dehydrogenase (ADH) assay as previously described [35].

\section{Additional file}

Additional file 1: Table S1. Sequences of Primers used for Gene

Constructs.

\section{Competing interests}

The authors declare that they have no competing interests.

\section{Authors' contributions}

WK, JF and TCJ carried out the gene cloning and the molecular genetic studies, TCJ participated in the design of the study UB conceived of the study and drafted the manuscript. All authors read and approved the fina manuscript.

\section{Acknowledgements}

WK was supported by an Innovation Research Grant awarded by Trinity College Dublin.

Received: 20 March 2015 Accepted: 8 April 2015

Published online: 28 April 2015

\section{References}

1. Lennartsson PR, Erlandsson P, Taherzadeh MJ. Integration of the first and second generation bioethanol processes and the importance of by-products. Bioresour Technol. 2014;165:3-8.

2. Kricka W, Fitzpatrick J, Bond U. Metabolic engineering of yeasts by heterologous enzyme production for degradation of cellulose and hemicellulose from biomass: a perspective. Front Microbiol. 2014;5:174.

3. Mosier N, Wyman C, Dale B, Elander R, Lee YY, Holtzapple M, et al. Features of promising technologies for pretreatment of lignocellulosic biomass. Bioresour Technol. 2005:96:673-86.

4. Chandel AK, Singh OV. Weedy lignocellulosic feedstock and microbial metabolic engineering: advancing the generation of 'Biofuel'. App Microbiol Biotechnol. 2011;89:1289-303.

5. Ruel K, Nishiyama Y, Joseleau JP. Crystalline and amorphous cellulose in the secondary walls of Arabidopsis. Plant Sci. 2012;193-194:48-61.

6. Peng F, Peng P, Xu F, Sun RC. Fractional purification and bioconversion of hemicelluloses. Biotechnol Adv. 2012;30:879-903.

7. Madhavan A, Srivastava A, Kondo A, Bisaria VS. Bioconversion of lignocellulosederived sugars to ethanol by engineered Saccharomyces cerevisiae. Crit Rev Biotechnol. 2012;32:22-48.

8. Weng JK, Li X, Bonawitz ND, Chapple C. Emerging strategies of lignin engineering and degradation for cellulosic biofuel production. Curr Opin Biotechnol. 2008:19:166-72.

9. Chiaramonti D, Prussi M, Ferrero S, Oriani L, Ottonello P, Torre P, et al. Review of pretreatment processes for lignocellulosic ethanol production, and development of an innovative method. Biomass and Bioenergy. 2012:46:25-35.

10. Hou X. Anaerobic xylose fermentation by Spathaspora passalidarum. Appl Microbiol Biotechnol. 2012:94:205-14.

11. Urbina H, Frank R, Blackwell M. Scheffersomyces cryptocercus: a new xylose-fermenting yeast associated with the gut of wood roaches and new combinations in the Sugiyamaella yeast clade. Mycologia. 2013;105:650-60.

12. Wanlapa L, Ancharida A, Motofumi S, Moriya O, Somboon T. Diversity and Fermentation Products of Xylose-Utilizing Yeasts Isolated from Buffalo Feces in Thailand. Microb Environ. 2013:28:354-60.

13. Zhang G, Lin Y, He P, Li L, Wang Q, Ma Y. Characterization of the sugar alcohol-producing yeast Pichia anomala. J Ind Microbiol Biotechnol. 2014:41:41-8
14. Nakatani Y, Yamada R, Ogino C, Kondo A. Synergetic effect of yeast cellsurface expression of cellulase and expansin-like protein on direct ethanol production from cellulose. Microb Cell Fact. 2013;12:66.

15. Wenger J, Schwartz K, Sherlock G. Bulk segregant analysis by highthroughput sequencing reveals a novel xylose utilization gene from Saccharomyces cerevisiae. PLoS genetics 2010, 6. 13;6(5):e1000942. doi: 10.1371/journal.pgen.1000942.

16. Schwartz K, Wenger JW, Dunn B, Sherlock G. APJ1 and GRE3 homologs work in concert to allow growth in xylose in a natural Saccharomyces sensu stricto hybrid yeast. Genetics. 2012;191:621-32.

17. Bera AK, Ho NW, Khan A, Sedlak M. A genetic overhaul of Saccharomyces cerevisiae $424 \mathrm{~A}(\mathrm{LNH}-\mathrm{ST})$ to improve xylose fermentation. J Ind Microbiol Biotechnol. 2011;38:617-26.

18. Matsushika A, Inoue H, Murakami K, Takimura O, Sawayama S. Bioethanol production performance of five recombinant strains of laboratory and industrial xylose-fermenting Saccharomyces cerevisiae. Bioresour Technol. 2009;100:2392-8.

19. Kato H, Matsuda F, Yamada R, Nagata K, Shirai T, Hasunuma T, et al. Cocktail delta-integration of xylose assimilation genes for efficient ethanol production from xylose in Saccharomyces cerevisiae. J Biosci Bioeng. 2013;116:333-6.

20. Karhumaa K, Fromanger R, Hahn-Hagerdal B, Gorwa-Grauslund MF. High activity of xylose reductase and xylitol dehydrogenase improves xylose fermentation by recombinant Saccharomyces cerevisiae. Appl Microbiol Biotechnol. 2007;73:1039-46.

21. Hector RE, Dien BS, Cotta MA, Mertens JA. Growth and fermentation of Dxylose by Saccharomyces cerevisiae expressing a novel D-xylose isomerase originating from the bacterium Prevotella ruminicola TC2-24. Biotechnol Biofuels. 2013;6:84.

22. de Figueiredo VL, de Mello VM, Reis VC, Bon EP, Goncalves Torres FA, Neves $B C$, et al. Functional expression of Burkholderia cenocepacia xylose isomerase in yeast increases ethanol production from a glucose-xylose blend. Bioresour Technol. 2013;128:792-6.

23. Tanino T, Hotta A, Ito T, Ishii J, Yamada R, Hasunuma T, et al. Construction of a xylose-metabolizing yeast by genome integration of xylose isomerase gene and investigation of the effect of xylitol on fermentation. Appl Microbiol Biotechnol. 2010:88:1215-21.

24. Walfridsson M, Bao X, Anderlund M, Lilius G, Bulow L, Hahn-Hagerdal B. Ethanolic fermentation of xylose with Saccharomyces cerevisiae harboring the Thermus thermophilus xylA gene, which expresses an active xylose (glucose) isomerase. Appl Environ Microbiol. 1996;62:4648-51.

25. Kuyper M, Winkler AA, van Dijken JP, Pronk JT. Minimal metabolic engineering of Saccharomyces cerevisiae for efficient anaerobic xylose fermentation: a proof of principle. FEMS Yeast Res. 2004:4:655-64.

26. Xiong $M$, Chen $\mathrm{G}$, Barford J. Alteration of xylose reductase coenzyme preference to improve ethanol production by Saccharomyces cerevisiae from high xylose concentrations. Bioresour Technol. 2011;102:9206-15.

27. Ma TY, Lin TH, Hsu TC, Huang CF, Guo GL, Hwang WS. An improved method of xylose utilization by recombinant Saccharomyces cerevisiae. J Ind Microbiol Biotechnol. 2012;39:1477-86.

28. Diao L, Liu Y, Qian F, Yang J, Jiang Y, Yang S. Construction of fast xylose-fermenting yeast based on industrial ethanol-producing diploid Saccharomyces cerevisiae by rational design and adaptive evolution. BMC Biotechnol. 2013:13:110.

29. Lee SM, Jellison T, Alper HS. Directed evolution of xylose isomerase for improved xylose catabolism and fermentation in the yeast Saccharomyces cerevisiae. Appl Environ Microbiol. 2012;78:5708-16.

30. Demeke MM, Dietz H, Li Y, Foulquie-Moreno MR, Mutturi S, Deprez S, et al. Development of a D-xylose fermenting and inhibitor tolerant industrial Saccharomyces cerevisiae strain with high performance in lignocellulose hydrolysates using metabolic and evolutionary engineering. Biotechnol Biofuels. 2013;6:89.

31. Baek SH, Kim S, Lee K, Lee JK, Hahn JS. Cellulosic ethanol production by combination of cellulase-displaying yeast cells. Enzyme Microb Technol. 2012;51:366-72

32. Kim S, Baek SH, Lee K, Hahn JS. Cellulosic ethanol production using a yeast consortium displaying a minicellulosome and beta-glucosidase. Microb Cell Fact. 2013;12:14

33. Yamada R, Taniguchi N, Tanaka T, Ogino C, Fukuda H, Kondo A. Direct ethanol production from cellulosic materials using a diploid strain of Saccharomyces cerevisiae with optimized cellulase expression. Biotechnol Biofuels. 2011:4:8. 
34. Yanase S, Yamada R, Kaneko S, Noda H, Hasunuma T, Tanaka T, et al. Ethanol production from cellulosic materials using cellulase-expressing yeast. Biotechnol J. 2010;5:449-55

35. Fitzpatrick J, Kricka W, James TC, Bond U. Expression of three Trichoderma reesei cellulase genes in Saccharomyces pastorianus for the development of a two-step process of hydrolysis and fermentation of cellulose. J Appl Microbiol. 2014;117:96-108.

36. Den Haan R, Rose SH, Lynd LR, van Zyl WH. Hydrolysis and fermentation of amorphous cellulose by recombinant Saccharomyces cerevisiae. Metab Eng. 2007:9:87-94.

37. Goyal G, Tsai SL, Madan B, DaSilva NA, Chen W. Simultaneous cell growth and ethanol production from cellulose by an engineered yeast consortium displaying a functional mini-cellulosome. Microb Cell Fact. 2011;10:89.

38. Fujita Y, Ito J, Ueda M, Fukuda H, Kondo A. Synergistic saccharification, and direct fermentation to ethanol, of amorphous cellulose by use of an engineered yeast strain codisplaying three types of cellulolytic enzyme. Appl Environ Microbiol. 2004;70:1207-12.

39. Wen F, Sun J, Zhao H. Yeast surface display of trifunctional minicellulosomes for simultaneous saccharification and fermentation of cellulose to ethanol. Appl Environ Microbiol. 2010;76:1251-60.

40. Saitoh S, Hasunuma T, Tanaka T, Kondo A. Co-fermentation of cellobiose and xylose using beta-glucosidase displaying diploid industrial yeast strain OC-2. Appl Microbiol Biotechnol. 2010;87:1975-82

41. Ha SJ, Galazka JM, Kim SR, Choi JH, Yang X, Seo JH, et al. Engineered Saccharomyces cerevisiae capable of simultaneous cellobiose and xylose fermentation. Proc Natl Acad Sci U S A. 2011;108:504-9.

42. Saitoh S, Tanaka T, Kondo A. Co-fermentation of cellulose/xylan using engineered industrial yeast strain OC-2 displaying both beta-glucosidase and beta-xylosidase. Appl Microbiol Biotechnol. 2011;91:1553-9.

43. Bond U. The Genomes of Lager Yeasts. In: Laskin Al, Sariaslani S, Gadd GM editors. Adv Appl Microbiol, vol. 69. Burlington: Academic Press; 2009. p. 159-82.

44. Libkind D, Hittinger CT, Valerio E, Goncalves C, Dover J, Johnston M, et al. Microbe domestication and the identification of the wild genetic stock of lager-brewing yeast. Proc Natl Acad Sci U S A. 2011;108:14539-44.

45. Monerawela C, James TC, Wolfe KH, Bond U. Loss of lager specific genes and subtelomeric regions define two different Saccharomyces cerevisiae lineages for Saccharomyces pastorianus Group I and II strains. FEMS Yeast Res. 2015;15:1-11.

46. Bettiga M, Hahn-Hagerdal B, Gorwa-Grauslund MF. Comparing the xylose reductase/xylitol dehydrogenase and xylose isomerase pathways in arabinose and xylose fermenting Saccharomyces cerevisiae strains. Biotechnol Biofuels. 2008;1:16.

47. Karhumaa K, Garcia Sanchez R, Hahn-Hagerdal B, Gorwa-Grauslund MF Comparison of the xylose reductase-xylitol dehydrogenase and the xylose isomerase pathways for xylose fermentation by recombinant Saccharomyces cerevisiae. Microb Cell Fact. 2007:6:5

48. Bajwa PK, Ho CY, Chan CK, Martin VJ, Trevors JT, Lee H. Transcriptional profiling of Saccharomyces cerevisiae T2 cells upon exposure to hardwood spent sulphite liquor: comparison to acetic acid, furfural and hydroxymethylfurfural. Antonie Van Leeuwenhoek. 2013;103:1281-95.

49. Hasunuma T, Sanda T, Yamada R, Yoshimura K, Ishii J, Kondo A. Metabolic pathway engineering based on metabolomics confers acetic and formic acid tolerance to a recombinant xylose-fermenting strain of Saccharomyces cerevisiae. Microb Cell Fact. 2011;10:2

50. Hasunuma T, Ismail KS, Nambu Y, Kondo A. Co-expression of TAL1 and $\mathrm{ADH} 1$ in recombinant xylose-fermenting Saccharomyces cerevisiae improves ethanol production from lignocellulosic hydrolysates in the presence of furfural. J Biosci Bioeng. 2014;117:165-9

51. Li BZ, Yuan YJ. Transcriptome shifts in response to furfural and acetic acid in Saccharomyces cerevisiae. Appl Microbiol Biotechnol. 2010;86:1915-24.

52. Zhuang J, Liu Y, Wu Z, Sun Y, Lin L. Hydrolysis of wheat straw hemicellulose and detoxification of the hydrolysate for xylitol production. Bio-Resources. 2009;4:674-86

53. Chandel AK, Kapoor RK, Singh A, Kuhad RC. Detoxification of sugarcane bagasse hydrolysate improves ethanol production by Candida shehatae NCIM 3501. Bioresour Technol. 2007;98:1947-50.

54. Grzenia DL, Wickramasinghe SR, Schell DJ. Fermentation of reactivemembrane-extracted and ammonium-hydroxide-conditioned dilute-acidpretreated corn stover. Appl Biochem Biotechnol. 2012;166:470-8.
55. Koppram R, Albers E, Olsson L. Evolutionary engineering strategies to enhance tolerance of xylose utilizing recombinant yeast to inhibitors derived from spruce biomass. Biotechnol Biofuels. 2012;5:32

56. Heer D, Sauer U. Identification of furfural as a key toxin in lignocellulosic hydrolysates and evolution of a tolerant yeast strain. Microb Biotechnol. 2008;1:497-506

57. Wallace-Salinas V, Gorwa-Grauslund MF. Adaptive evolution of an industrial strain of Saccharomyces cerevisiae for combined tolerance to inhibitors and temperature. Biotechnol Biofuels. 2013;6:151

58. Almario MP, Reyes LH, Kao KC. Evolutionary engineering of Saccharomyces cerevisiae for enhanced tolerance to hydrolysates of lignocellulosic biomass. Biotechnol Bioeng. 2013;110:2616-23.

59. James TC, Usher J, Campbell S, Bond U. Lager yeasts possess dynamic genomes that undergo rearrangements and gene amplification in response to stress. Curr Genet. 2008:53:139-52.

60. Ekberg J, Rautio J, Mattinen L, Vidgren V, Londesborough J, Gibson BR. Adaptive evolution of the lager brewing yeast Saccharomyces pastorianus for improved growth under hyperosmotic conditions and its influence on fermentation performance. FEMS Yeast Res. 2013;13:335-49.

61. Wei N, Quarterman J, Kim SR, Cate JH, Jin YS. Enhanced biofuel production through coupled acetic acid and xylose consumption by engineered yeast Nat Commun. 2013:4:2580

62. Richardson SM, Wheelan SJ, Yarrington RM, Boeke JD. GeneDesign: rapid, automated design of multikilobase synthetic genes. Genome Res. 2006;16:550-6

63. Jansen G, Wu C, Schade B, Thomas DY, Whiteway M. Drag\&Drop cloning in yeast. Gene. 2005;344:43-51.

64. Taxis C, Knop M. System of centromeric, episomal, and integrative vectors based on drug resistance markers for Saccharomyces cerevisiae. Biotechniques. 2006:40:73-8.

\section{Submit your next manuscript to BioMed Central and take full advantage of:}

- Convenient online submission

- Thorough peer review

- No space constraints or color figure charges

- Immediate publication on acceptance

- Inclusion in PubMed, CAS, Scopus and Google Scholar

- Research which is freely available for redistribution 